\title{
The Spatial Dimension of Landscape Studies: New Trends and Rationales for the Development of the Discipline of Literary Geography
}

\author{
Jianjun Kang ${ }^{1,2}$ Yinghua Lin ${ }^{1, *}$ Jiyuan Zhai $^{1}$ \\ ${ }^{1}$ School of Geography and Environment, Liaocheng University, Liaocheng, Shandong 252059, China \\ ${ }^{2}$ Institute of Literature, Jiangxi Academy of Social Sciences, Nanchang, Jiangxi 330077, China \\ *Corresponding author.Email: akanghao@vip.163.com
}

\begin{abstract}
The study of the landscape is an important element in the study of literary geography. Regional differences lead to landscape differences, which become literary spaces under the writers' pens each with its characteristics. In the study of literary geography, through the study of ancient and modern writers and works, literary proliferation, literary reception, regional geographical differences, and the dimension of the spatial landscape have all played an important research value, forming the highlight of the study of the discipline of literary geography. Among them, the dimension of the spatial landscape has become a hot spot. Therefore, regarding the enrichment of landscape types and the interrelationship between landscape and space, it will have a very great impact on the disciplinary construction of literary geography, and enrich the new progress of literary geography in terms of disciplinary foundation and value orientation. Writers' landscape descriptions make the image of the world clearer and more vivid. As far as the ecological perspective is concerned, the process of human conquest of nature also has to conform to the counteracting force of nature, and the dual opposition between man and nature has become the mainstream concept of literary writing. It is under the guidance of this concept that issues such as ecological crisis and nature's revenge have also entered the research scope of literary geography. The role of the spatial landscape is to create a renewed world and the protection of nature by man in literary works and the restoration and reconstruction of ecological balance. The repetition of themes such as the return and reconstruction of the harmony between man and nature is also a new trend in the development of the discipline of literary geography and a new rationale for the next step of research.
\end{abstract}

Keywords: Geographical landscape, Spatial dimension, Literary geography, Creative development, Eco-criticism.

\section{INTRODUCTION}

The study of the landscape has been transformed from a microcosmic place to a macrocosmic place. The existing research shows a clear spatial dimension and the spatial turn, and

*Funds: Identify applicable sponsor/s \& Fund project:

1. Special Research Project of Shandong Province for Building New Frontiers of Opening Up, 2021;

2. Social Sciences Popularization and Application Research Project of Shandong Province, 2021;

3. Cooperation and Collaborative Education Project between Universities and Enterprises of the Ministry Of Education, 2021:

4. National and Regional Research Center, Ministry of Education - Pacific Island Countries Research and Innovation Fund Project, 2021. many researchers for sociology, anthropology, culture, and geography have begun to focus on geographic landscapes and the symbolic systems they convey. The results of the research are particularly concerned with how geographic landscapes are endowed with certain symbolic meanings, or how certain symbolic meanings are artificially endowed in particular landscapes. The hotspot of the research also indicates, in particular, that in the process of artificially reshaping the geographical landscape to express the spirit of nationalism, and in the process of promoting and deepening the research of the new cultural geography and landscape geography and its inner connection with "geopoetics" through the specific 
interpretation of the symbolic meaning of the literary geographical landscape, the spatial In the process of advancing and deepening the research of new cultural geography and landscape geography and their inner connection with "geopoetics", the spatial properties of landscape research and the complementarity of landscape research in space have become the hot topics of current research. The types of landscape and the criteria of identification, such as the spatial analysis method and the regional differentiation method, reflect the obvious idea of cultural geography and provide the methodological support for the horizontal and vertical research of literary geography.

\section{THE SPATIAL LANDSCAPE DIMENSION IN LITERARY WORKS BECOMES AN IMPORTANT TURN IN THE CONSTRUCTION OF THE DISCIPLINE OF LITERARY GEOGRAPHY AT PRESENT}

The study of spatiality is an important element in conducting the analysis of literary samples, and spatiality is an important attribute of textual studies. What kind of literary geography exists in the study of literary spatiality, a multidisciplinary cross-border fusion? In-depth talks and interviews all provide practical training in testing readings and creative writing for the crossover and integration of disciplines. In the eyes of researchers from different professional backgrounds, poetic space and geographic space enrich the content of literary and geographic studies, and make space in the current context gradually grow into a more important concept than time. By exploring different aspects of spatiality in literary studies, students and faculty members sorted out the spatial turn in the whole field of literary theory and saw the necessity of cross-border integration of multiple disciplines in the context of the new liberal arts education. As a marginal and cross-disciplinary discipline, literary geography should be integrated into a more reasonable knowledge structure in the process of building the new liberal arts, and it should also present a more obvious character of literature and geography[1].

From the vast works on literary geography by famous researchers such as Zeng Daxing, Xia Hanning, Zou Jianjun, and Mei Xinlin in China, to the contributions to Chinese literary geography by renowned professors with international perspectives such as Professor Amamura Yuiji (和してー) from
Japan, Professor Jung Yulo (정우락) from Korea, and Professor I Lo-fen from Singapore, as well as the contributions to literary geography from Guangzhou University The discipline of literary geography is moving toward a new direction. The discipline of literary geography is making great strides toward a "twin peaks" pattern with the discipline of literary history.

\subsection{Geographical Space and Literary Landscape Have Built the Disciplinary Foundation of Modern Literary Geography}

Literary geography is a branch of geographic science that studies the relationship between literary works and people and places. It takes writers and works as intermediaries and texts and stories as the core, focusing on the two-way interaction and internal connection between literary works and geographical environment. The creation space and presentation effect of literary works can see that poetic space exists in literary works inch by inch. All geographical spaces that originate from real life and are higher than the real world, because of their perceptibility and shareability, such poetic spaces are then highly realistic in the interpretation and reading of texts and highly authentic in reflections. And the further development of literary geography should take the disciplinary orientation of literary geography as the benchmark, and further increase the in-depth research on geographical space and literary landscape.

In the 1980s, Professor Yuan XingPei of Peking University and others began to study the regional aspects of literature, and with this as the guide, the research object of literary geography is no longer confined to the superficial study of the geographical distribution of literary works but goes deeper into the investigation of the geographical ideas of the works themselves, including the geographic knowledge used in the works and the creation of the spatial landscape dimension, etc. As a result, literary geography starts a dialectical analysis of the relationship between geography and literature with critical thinking.

Later, Prof. Zeng Daxing's Introduction to Literary Geography and Prof. Xia Hanning's Study of Jiangxi Regional Literature is dedicated to exploring the geoscientific contents of spatial design and landscape layout contained in literary works and integrating the knowledge of urban literary geography, regional literary geography, 
and intergenerational literary geography from the core concept of the relationship between literature and geographical environment. Its research covers the research object and disciplinary orientation of literary geography; the influence of geographic environment, natural environment, and human environment on literature; the geospatial elements, spatial construction, geographic environment, and the literary landscape in literary works, and the spatial and regional division of literary works from a geographic perspective. The methodology of literary geography research, including the method of tethering, spatial analysis, regional differentiation, regional comparison, and geographical imagery research, integrates the basic principles and basic steps of literary geography with dialectical thinking and solves several practical problems at a time when the discipline is not yet firmly established.

\subsection{Describing Literary Landscapes and Redrawing Literary Maps Have Been the Interest of Literary Geography in Recent Years}

In recent years, literary geography aims to describe literary landscapes, redraw literary maps, and distill the characteristics of human geography. While grasping the function of geography in depicting spatial dimensions, it relies on literature's use of practical dimensions to gain insight into the geographical elements in literary history.

Spatiality is the keyword of literary and cultural studies nowadays, and it focuses on the "spatial turn", providing a new approach to the traditional literary analysis of time and history. Contemporary Frontiers of Western Scholarship - Spatiality (by Robert T. Tally Jr., translated by Fang Ying, Peking University Press, 2021) is a serious text worth reading and discussing in-depth this year in the study of literary spatiality.

On the one hand, literary geography emphasizes the restoration of scenes, the presentation of real Spatio-temporal scenes in different time dimensions. On the other hand, literary geography emphasizes the restoration of literary maps and spatial landscapes and explores the changes of literary directions from the perspective of macro-geography. The disciplinary construction of literary geography is an organic interplay of literature and geography disciplines. Geographic space and geographic landscape undoubtedly have a great influence on literary creation, whose selection of topics, characters, and social background depends on the author's knowledge of the human geographic environment, and the author's insights into different geographic environments and spatial landscapes accumulate to form a strong literary heritage and give literary works a distinctive color[2].

By exploring the relationship between literature and geography, people understand the impact of the interaction between the two on the development of the discipline of geography and thus lay a good foundation for the development of the discipline of human geography as a whole. The series "Literary Geography" has published the works of more than 200 researchers in literary geography on the one hand, and united the Chinese Society of Literary Geography on the other, which can be considered as a great contribution to the development of the discipline of literary geography.

\subsection{Further Enrichment of Landscape Type Studies and Further Expansion of the Extension of Landscape Studies}

The relevant landscape types and identification criteria, such as spatial analysis method and regional differentiation method, reflect obvious cultural geography ideas and provide methodological support for the horizontal and vertical study of literary geography.

On the one hand, it is the countryside, with green mountains and scenery and simple people; on the other hand, it is the industrial area representing modern industrial civilization. These are two civilizations that coexist and are very different. The geographical separation leads to nowhere to find "home". For the writer, "home" is no longer a "fixed place", but a "place of constant search". The writer's later works seem to feel the pain, contradiction, hesitation, and suppression of the emotional experience. Only the hometown can be close to the origin, and going home is to return to the closeness with the origin.

The creation of the discipline of literary geography began to shift from focusing on special studies of regional literature to comprehensive research, dividing regions against the background of different dynasties to ensure that research results are more in line with the human geography of specific historical periods, and on this basis, strengthening the study of peripheral areas to enrich the elements of literary geography scenes.

It's needed to propose and address the ways and mechanisms by which geography influences 
literature. The geographical environment influences the "writer's life consciousness" through "geographical objects" and geographical events. The "writer's life consciousness" influences the creation of literary works through the "writer's temperament and personality". At the same time, literary geographical landscape, geographical landscape, and literary landscape have become the most important themes and contents of literary geography research. Chinese literary geographers have not only defined the connotation and extension of "literary geography landscape", but also established the criteria for identifying "literary geography landscape" and fully explored the multiple values and meanings of "literary geography landscape".[3] The multiple values and meanings of "literary geography landscape" have been fully explored. On this basis, Chinese literary geographers have conducted in-depth research on a large number of "literary geographic landscapes". These investigations have not only opened up a new field of traditional literary research and enriched the research content of literary geography, but have also been borrowed by human geography, cultural geography, tourism geography, and other disciplines, and have attracted the attention of the entire geography community. (by Liu Shuangqin, Liu Zhen, Towards a Mature Literary Geography: An Overview of the "10th Anniversary of the Chinese Society of Literary Geography - Jiangxi High-end Forum")

In addition, the study of urban literary geography, emphasizing the axial role played by cities in literary geography, exploring the changing history of cities, and deeply interpreting the imaginative expressions in literary works have become important vehicles for the study of modern literary geography.

Many of the achievements of Prof. Chen Shangjun, Prof. Dai Weihua, Prof. Hu A'xiang, Prof. Zhang Weiran, and others have further opened up new paths of literary geography research from the perspectives of historical geography, cultural geography, landscape geography, as well as new methods and new thinking of some young scholars.

In the author's work, place refers not only to the touching natural landscape but also to the composite space composed of memory and culture. It is the spiritual home that supports human existence and gives them a sense of belonging. Memory is not a return to the past, but a rewriting and nostalgia that leads to identity formation and home belonging. The process of finding the origin of the family in the life story is also the process of returning to the traditional land and integrating into nature. In the journey back home, the natural landscape along the way is full of meaning, and the final natural forms together constitute the ultimate meaning of the journey of life.

\section{THE SELF-CREATION AND SELF- REPLICATION OF THE LANDSCAPE DERIVES A MORE EXCITING LITERARY WORLD}

In the process of modernization, culturalecological landscapes are increasingly differentiated and give rise to forms of self-creation and self-replication.

Cultural ecological landscapes are not only collective entities; each individual in them is an ecological landscape. The environment with human characteristics refers not only to the external environment but also to the internal environment, i.e., the internal landscape of the inner world and the psycho-cultural imagination, which is no less functional than the external natural and physical environment. The relationship between cultural ecology and literary creation is interdependent. Creativity is an important factor in all culturalecological landscapes. Although the ways and degrees of creativity in different fields are quite different, it is clear that art and literature constitute a cultural-ecological landscape in which creativity is at the very center. They serve as both a laboratory of cultural possibilities and a repository of various creative processes and spaces for innovation. These creative processes are found everywhere in the cultural system, and they function as forces of renewal and evolution; however, they can only be carried out relatively freely in the arts.

\subsection{Literature's Description of Spatial Landscape Gradually Deepens}

The author is the narrator of a literary spatial text, and in producing a stitched representation of a certain world, the narrator also creates or discovers that world presented by the narrative. For the reader, that narrative gives an image of that world, which approximates a map, and the literary mapping in a given narrative can become part of future surveys, chants, and narratives, or of future narrative maps. Maps are not strictly imitative representations of existing space, but rather imaginative projections of space that can be used 
for people's lives. By recognizing the spatiality of literature, future literary maps may find a hitherto unforeseen way to understand the world encountered and the world that exists only in the human imagination.

The writer's works take the concept and practice of "place consciousness" as their theme, and from the personal trauma of childhood, they combine the understanding and pursuit of "place" with the contemplation of the state of human existence and spiritual home, reflecting the human spiritual identity and sense of belonging to a place. It reflects the human's spiritual identity and sense of belonging to the place. From the writer's growing experience, the unique regional cultural imprint of his hometown is the source of spiritual memory for the construction of local consciousness in his works. Over the years, the writer's spiritual and regional alienation from the local culture has led to his self-divisiveness[4]. The melancholy and loss brought about by the contradiction between human family culture and discrete reality prompt the writer to turn to the wilderness again and again to seek comfort and identity. This can be seen in the writer's works: human beings construct their own identity through the perception of place. The writers' works awaken the moral connection between human beings and the material world. Therefore, the emotional attachment generated by the interaction between humans and "place" helps to form the spirit of place, and the place thus becomes the "homeland" of human beings. The writers' "sense of vernacular" based on the environment and spatial imagination also constitutes an important element in the construction of the writers' identity.

\subsection{The Role of Spatial Landscape Is to Create a Newer World}

Robert describes the role of literature in terms of "projecting a world". The act of writing itself can perhaps be seen as a form of mapping or cartography, where authors are mapmakers who map the real and imagined spaces of their world in different ways. The reader is a reader of texts as well as a reader of maps. Space has always existed and has a vast history. What is spatiality? Kant saw space as the container of all things. The recent spatial turn in literary and cultural studies is largely a product of the post-present condition. Literary mapping is the primary way to demonstrate literary spatiality. Writers engage in a cartography-like activity by which authors present us with a unique literary space. A narrative is a form of world creation.

"Everything is related to everything else." Ecoethical research studies the "relationship between man and nature" in literature, starting from the relationship between things. Nature in the field of environmental ethics is an ecological whole, including nature and all living things in nature. The relationship between man and nature mainly includes the influence of nature on man, the whole of nature, the relationship between everything and man, man's conquest, control, transformation, plundering and destruction of nature, man's praise and aesthetics of nature, man's protection of nature and the restoration and reconstruction of ecological balance, the return, and reconstruction of harmony between man and nature, etc. In his works, the author not only profoundly praises the grace of nature to human beings, appreciates the company, consolation, and enlightenment of nature to human beings, and through the reflection on the relationship between human beings and nature, human beings and themselves, he deeply explores the path and mode for human beings to return to nature and live in harmony with nature and has certain values.

\subsection{The Existence of a Sense of Place and the Variation of the Sense of Space}

In life, people often feel anxiety, perhaps from the future, perhaps from life, and in spatiality, the author believes that anxiety comes from not knowing whether one is acting rightly or not and that one must have the freedom to choose the right or wrong path. Thus, the feeling of anxiety is the recognition from the heart of the man of the inescapable freedom. But if freedom is the source of existential anxiety, then for Sartre, freedom is also the way to overcome anxiety. In other words, to feel anxiety is to have anxiety when people's freedom is limited in one way, because people cannot have the feeling of freedom, and yet people can resolve it by acquiring freedom in another way. Each person must have the freedom to create the meaning of his or her existence: that is, each subject should organize the parts of his or her life in a meaningful way to establish a sense of "place" and purpose in the world.

Poetics space crosses or even confuses on real space and fictional space, exists in the transition and reorganization of literary works and real life, although through the author's artistic processing, only one kind of geographic space can be generated 
that can be expressed, different readers will interpret a thousand different kinds of Hamlet. Many readers will substitute the real geographic space into the literary work and reflect on the literary work according to their own life experiences and life encounters, so this type of geographic space exists significantly less than the literary work and poetic space in the readers' minds. Cognitive mapping is the structured mapping of information according to one's perception, which is equivalent to a narrative of an event that, as a way of expressing experience and characterizing reality, is a response to, and can be influenced by, different spatial organizations[5].

The writer's poems are thematically, visually, and artistically different from the usual praise of nature and contain a rich and unique sense of vernacular. As an eco-poet, the writer's sense of vernacular existence is mainly derived from his childhood memories of "place" and his special experience of leaving his hometown to roam the world. His poetry on the theme of "place" reflects the poet's pursuit of his spiritual home and his infinite nostalgia for his beautiful childhood. It is the fermentation, transformation, and generation of childhood memories that inspire the poet's fictional imagination and enable him to artfully explain the inseparable relationship between himself and his home. "Place" is the spiritual home where human beings survive and live. The new era of ecological ethics is concerned with the "environment" of human existence, it emphasizes that "human beings are inseparable from the environment from the body to spirit."

Each person has his unique sense of place, and each person's trajectory of movement is different, and thinking is also different, and the person is the subject of the sense of place, and the sense of place will follow the change of the subject, and when the subject exists meaningfully in space, then the unique sense of place that follows him is also meaningful.

The close observation of spatial criticism is the spatial turn that has dominated in recent years. Spatial theory in the field of literary studies draws out the significance of poetic theory in the structure and inner space of the literary text space, taking into account the changes in the spatial environment of literary criticism, such as landscape and geographical factors. In the interpretive approach to literary texts, the context of the story lies not only in the textual space and environment but also as a symbolic and related system that will be related to other literary elements, such as the narrative and thematic meanings of the text. In traditional literary studies, people tend to focus on the relationship between literature and its spatial environment.

The urban crisis is becoming more and more serious. The development of society has led mankind to re-examine and redefine the concept of place. From the initial natural wilderness and countryside to the metropolis, the traditional concept of the environment has further expanded to include man-made landscapes such as cities. The emergence of cities has dramatically changed the human sense of place, and the globalization of the economy and the development of media technology have caused spatial flux. "The inner life of the metropolis has expanded into a movement like a giant wave, transcending national or international regional boundaries and becoming a huge function beyond its actual physical borders." Modern commerce and industrial production in cities have upended traditional ways of life, and the movement of people, information, and capital has driven spatial mobility and reshaped various social and cultural relations in cities. It is undeniable that the past idyllic life has become history, replaced by urban life, and the natural vernacular memory has gradually evolved into the urban vernacular memory.

The work describes the joy of nature feeling the fusion of all things. The work uses words to arrange vivid and original images in an attempt to restore the natural scenery as it is, such as cold and bright streams and small but hard rocks. The author feels great joy in embracing nature, baptized by nature from the body to mind, and then sings a song in praise of the tranquility of nature and the harmonious coexistence of all things.

\section{DISCIPLINARY CONSTRUCTION, VALUE ORIENTATION, DEFINITION, AND RESEARCH METHODS OF LITERARY GEOGRAPHY IN THE DIMENSION OF SPATIAL LANDSCAPE}

The monograph series "Literary Geography" summarizes and enhances the theoretical knowledge on the disciplinary construction, value orientation, definition, and research methods of literary geography, based on the frontier of human geography development, highlighting the logic and empirical nature of geography, also integrating humanities and transforming into the pursuit of 
spiritual literacy, one can be happy to see that the garden of literary geography, a cross-disciplinary discipline, will be more flourishing.

Nostalgia is the most important way to express love for the land complex, and it is a more lasting and difficult to express emotional reaction that occurs in a place with fond memories like home. This emotional response often gives people a sense of long-lost belonging. The perception of space comes first and foremost from the attachment to one's homeland. Each continent has its great regional spirit. It is a great fact that every Chinese person is attracted to a specific region. The writers' own "great regional spirit" is affectionately called "spiritual home", which is a magnificent landscape that carries all the writers' sincere feelings in their hearts. Writers spent many unforgettable moments in their beautiful hometowns as children, which formed the base of their writing.

In Emerson's time, America was still a wilderness. Like his fellow writers and Romantic writers, Emerson had a unique love for the wilderness of early North America. The concept of "wilderness" is important in the history of American environmental thought. Emerson and Thoreau emphasized the importance of wilderness. Since the discovery of the New World, the emptiness and richness of the North American wilderness had attracted a large number of dreamers from Europe who held to the "American Dream". For the writers, the North American continent was different from the abused lands of ancient Europe. It was full of life and vitality because it was a new opportunity for the wilderness to flourish first.

In the field of modern space theory, political culture and ideology play an important role in the production of space, giving literary space a profound historical, cultural, and social character. And in modern literary studies, the spatial critique of literature has entered literature from many aspects. Studies include postcolonialism, feminism and gender criticism, and the study of popular culture and style. Literary spatial critique has also developed into a multidimensional interdisciplinary vision of spatial theory and anthropology, geography and architecture, as well as the interactive interpretation of literary research practice and spatial theory, providing new horizons and theoretical growth points for research. And in the field of spatial theory, literature is essentially a kind of local production, and literary works not only provide a simple description from a geographical perspective, but also provide a way to understand and explain the world, a kind of geographically based experience yet an inclusive field; literature is a product of society and reality, but literature also plays a role in society and the real world, influencing the actual process of geography and social development. Therefore the discipline of literary geography is possessing a good development momentum, and with the continuous enrichment of research results, the discipline has a wide range of application prospects in the future[6].

\subsection{The Imaginary Space of Poetics Will Continue to Extend and Become a New Literary Landscape}

The imaginary space of poetics can exist in the literary works, or it can be overwhelmed by the eight extremes, and the gods can travel to a new geographical and poetic space, which is deconstructed by the author's fiction and the reader's secondary connection. The secondary imagination of the poetic space has a very different sense of life. Literary mapping requires a method of reading and interpretation that is attuned to narrative spatiality, just as Ahab did when he delved into the map to find Moby Dick, so that people can find themselves and the space people are in constantly being rewritten and redrawn when they read the map, and this is the said social space. The main body of this group's presentation is to dig deeper into the cooperative tendency and development vein of literature + geography by examining three aspects: how people perceive space in the literary world, the path design and mapping of literary geography, and the turn of spatial poetics and the representation of void space.

Spatiality in literary works is not only linked to real existence but also applies in the world of nothingness. Franz Kafka, one of the representative writers in the twentieth century who specializes in "nihilism", also embodies "nothingness" as a subject in space in his modernist short story The Metamorphosis, which portrays Gerry Gaul as a "non-existent" person. This makes the reader a participant in something like a "game", i.e. an isolated imaginary world, where the author becomes God and gives them the power to the author becomes God, giving them the experience card to wander through the world of the text and peer into the life of the protagonist, while also tempting them to bring themselves into the shell of the protagonist, to fill the gaps in the text with their 
consciousness, to personally experience the pain of the protagonist's spiritual emptiness and the corresponding emotional resonance, to achieve a three-effect interaction of the author, the reader and the text in harmonious coexistence.

\subsection{The Writer's Landscape Description Makes the Image of the World Clearer and More Vivid}

The dualism of the past has emerged two modes of spatial awareness: the perspective and epistemological mode of "first space", which focuses on the materiality of the concrete image of spatial forms and the things that can be described according to experience; "second space" is the perception and construction. The "second space" is a mode of perception and construction, which is conceived within the idea of space, and is derived from human mental activity, and reproduces the exploration and reflection of spatiality in the form of perception. The image of poetry does not depend solely on the language of poetry itself, and is not constrained by common sense or rational thought; the author may not be able to provide the reader with an image of the past but makes the poet's image clearer. Through this, the artistic turn of poetry through spatiality will greatly promote the development and study of spatial poetics[7].

The misconception of man's conquest of nature has affected countless people, and the dual opposition between man and nature has become the dominant concept. It is under the guidance of this misconception that human beings have treated nature without regard to the consequences, and the ecological crisis has become more and more serious. Throughout history, from the beginning of the invention of the steam engine to today's space travel, mankind's desire to conquer space has become stronger and stronger, and space competition has become more and more intense. Humans can take up farmland to build cities, and humans can cut down trees on mountains to build railroads. Humans are discharging large amounts of toxic wastewater and sludge directly into rivers and lakes for economic benefits. Humans have "conquered" the earth. Scholars are not afraid of nature at all, let alone the ecological ethics of love, compassion, and care for nature. In the eyes of humans, nature is seen as a passive image that is slaughtered by others. Nature is not passive; the mysterious power of nature is unknown to us. There are many natural phenomena, such as the cycle of the seasons, the alternation of day and night, the rising and falling of the tides, and the blossoming and falling of flowers, that humans cannot explain or change; these are the mysterious laws of nature.

\subsection{The Guidance of Maps Can Sometimes Make Scholar Dependent and Even Lost}

Spatiality is an important critical concept and a subject of much attention in the field of literary and cultural studies in recent years. As an emerging critical method, the study of spatial issues breaks through the traditional perspective of literary criticism and theoretical analysis. It reconstructs the real society in a fragmented way and shows the world in a new way. And maps are important and direct access to information for making spatial interpretations. Cartographers often take advantage of the above psychological activities of readers and combine them with their own needs, distorting and transforming spatial data and information in the process of cartography to construct a new literary map, to achieve their purposes. For example, Columbus deliberately tampered with the data of navigation charts so that his successors could not directly access the abundant resources; Western writers consciously or unconsciously created the image of the "other" in their classic works to justify the myth of empire, advocate imperial order, and emphasize the idea of obedience to white colonizers. In the course of the expansion and decline of imperialism in the late 19th and early 20th centuries, an analysis of the works of famous British writers reveals the continuity and evolution of imperial consciousness, the imperial discourse followed in these texts, and the imperial consciousness of Eurocentricity, Western advancement, and white superiority. The most classic British postcolonial novel would be Joseph Conrad's Heart of Darkness. The novel deals with the conditions of the British colonies in Africa in a multifaceted and multifaceted way and is a typical example of postcolonial literature.

In conclusion, spatiality permeates all aspects of our lives and directly or indirectly affects our selforientation. People must both accept the guidance of existing maps so that they do not lose themselves in the vast sea of people. They also need to break the confinement of the existing maps, push the boundaries of the old and reform the new to meet the growing material and spiritual needs of people. 


\section{CONCLUSION}

All in all, the writing of the landscape of space also leads to a positive interaction between authors and readers.

Indeed, the formation, development, and evolution of culture are always influenced by geographical conditions, and culture reflects the natural environment in the landscape. Romantic writers' perception of the environment, writers' environmental awareness, and the shaping power of literary works on readers have important insights for people to improve the environment and solve the environmental crisis. Reflecting on the writers' imagination of nature in their literary works, reconstructing people's values, changing people's worldview with the power of literature, saving the earth, and saving humanity are the aims of Bethe's research practice of eco ethics.

Once a culture is formed, it has certain stability. If the role of geography is not sufficient to overcome this stability, it will not have an impact on cultural change. Moreover, as human society continues to progress, the constraints of geography on human beings are increasingly diminishing. However, culture and its landscape will never disappear in response to the geographical environment. The role of the natural and human environments on the human landscape is reflected in all aspects of the landscape system. In ancient times, the level of social productivity was extremely low. The living and production activities of primitive human beings were restricted by a specific geographical environment and had to adapt to certain natural conditions. The formation of China's colorful regional culture is the result of both multi-ethnic integration and the long-term effect of complex and diverse geographic environments.

For a long historical period, space existed only as an established place for social relations and operations, and the absence of space in social theory largely obliterated the imaginative power of geography. In terms of literature, narrative literature, which portrays the psychology of characters, is a temporal construction of the unfolding of space, while space becomes a drama of character development staged like a scene as a "stage".

\section{AUTHORS' CONTRIBUTIONS}

Jianjun Kang was responsible for the whole thesis design and wrote the manuscript, Yinghua Lin wrote the manuscript and the 3rd paragraph of the whole thesis, and Jiyuan Zhai contributed to revising and editing the thesis.

\section{REFERENCES}

[1] Li Zhongfan. The role of geographic doctrinal resources in the construction of literary geography [J]. Lanzhou Journal, 2015(06):5358 .

[2] Liu YJ. The Rise of Literary Geography as a Chinese Discourse - A Literature Study Based on the Proceedings of the Seventh Annual Conference of the Chinese Society of Literary Geography [J]. Social Science Dynamics, 2018(12):99-106.

[3] Du Huaping. A sign of the construction of the discipline of literary geography--Reading Zeng Daxing's Introduction to Literary Geography [J]. World Literature Review (Higher Education Edition), 2018(01):180186.

[4] Zhang Yuan Yue. From literary territory, literary geography to literary map - literary geography in spatial perspective [J]. Nankai Journal (Philosophy and Social Science Edition), 2018(03):149-158.

[5] Liu Qinghua. The construction of Sinology from literary geography [J]. Journal of Linyi University, 2018,40(02):47-57.

[6] Zeng Daxing. Six research methods of literary geography [J]. Chinese Forum, 2017(01):282302.

[7] Zuo Peng. Review of theoretical research on literary geography $[\mathrm{J}]$. Social Science Dynamics, 2017(04):10-17. 